\title{
Using Oral Presentations to Improve Task Response in Writing
}

\author{
L. Paul MANTHA*, Zi-qi LIU and Dan-dan WANG
}

Sino-Dutch Biomedical and Information Engineering School of Northeastern University, Shenyang, China

${ }^{*}$ Corresponding author

Keywords: Oral presentations, Task response, Writing.

\begin{abstract}
International Language Tests such as IELTS (International English Language Testing System) and TOFEL (Test of English as a Foreign Language) in their long writing component employ Task Response as one of the four scoring criteria. Task Response operates at a global level, it examines how well an argument is presented and supported. This paper proposes a method to improve Task Response through the use of Oral Presentations with both formative written feedback and dual mode interactive feedback post-presentation. In addition suggestive feedback during the preparation phase of a presentation. At the beginning of the first class and again at the end of the course students were required to write an essay of 250-300 words on an IELTS/TOEFL style question. A comparison of task Response in both set was conducted and showed a marked increase in all three areas that were examined. The paper concludes with a discussion of factors: Dual Mode Interactive Feedback, Summary Requirement and PowerPoint Structure that may have an impact on course instruction and outcomes.
\end{abstract}

\section{Introduction}

All students from non-English speaking countries must take either IELTS or TOFEL if they wish to study at a university or college in an English speaking country. One of the more challenging parts of these tests for Chinese students is the long essay. TOEFL lists development and organization [1] as two important parts in accessing the quality of an essay, while IELTS includes them as part of Task Response. [2] Research has shown that students are capable of learning from their own errors [3] and the amount they are capable of learning depends on the feedback they receive with speed [4] emphasis [5] higher level [6] and comprehensibility [7,8] being better. English Language Education in China is moving from one of rote memorization to one based on knowledge and skills. [9] This paper demonstrates that through the use of Oral Presentations and the provision of rapid and understandable feedback focused on a single, more global level can improve student writing.

\section{Teaching Method}

The course was taught over one semester with a total of 32 instructional hours, two hours a week for 16 weeks. At the start of the first class, a long writing of 250-300 words was assigned and the students given 50 minutes to complete it. In the second half of the class the course was introduced, they would work in groups of three and make a total of 6 presentations that feedback on would be provided, but not graded. They would also make a Mid-Term Presentation and a Final Presentation which would be graded.

Presentation and PowerPoint Rules the PowerPoint presentations were limited to 6 slides: Title, Introduction, Support I, Support II, Support III and Conclusion. Each slide was also limited to having a maximum of five lines containing a maximum of five words. The limited amount of text was intended as a means help maintain feedback at higher beyond the sentence levels. The structure of the presentation with Introduction, three supports and a conclusion followed five paragraph writing structure available online [10] The structure also provided limited space which meant that supporting ideas faced similar restrictions to those imposed by a 250-300 word essay. Thus ruling out the often semi-incoherent ramblings of the shotgun approach, try to say as many disorganized things as possible 
while hoping to say enough of the right things to receive a passing grade. Thus, the development of the presentation would have to be more focused and raise questions of the relevance of details.

\section{Presentation Classes}

Each student group would present their topic. While they were presenting the instructor would enter the topic name into the feedback form, and complete the form. At the end of the presentation the Instructor would choose one or two things that were done the best and one or two things that needed improvement to comment on.

\section{Feedback and Preparation Classes}

At the beginning of the class the Instructor would inform students to raise their hand if they had questions about the feedback they received or if they required some assistance on the next presentation. Then the Instructor would move from group to group providing assistance as requested. The students would spend the class working on their next presentation.

\section{Mid-Term and Final Presentations}

These two classes served the purpose of providing gradable work on which the course final mark could be based. The Mid-Term also provided graded feedback, which is taken more seriously, by some students, than ungraded feedback.

\section{Study Method}

Participants 121 First year students at a Chinese National University who were taking an Oral English class as part of their College English lessons.

\section{Data Collection}

At the beginning of the first class students were given a writing task. They had 50 minutes to write a 250-300 word essay on a topic that was chosen from a list of TOFEL long writing questions. Both question required the same style of response. In Writing I the students were required to state the type of learning style they preferred while in the Writing II they had to decide which type of class they preferred, large or small.

\section{Study Organization}

The student writing were graded by three criteria: Clear Position, Topic Development and Relevance/Focus using a five point Likert scale. Which was derived from an examination of IELTS and TOEFL public descriptors. Clear Position Scale 1- unclear, questionable responsiveness 2generalizations Position does not address question 3-Position does not address all parts 4- Clear, but limited 5- Provides clear summary of position that addresses all parts Topic Development Scale 1 Serious disorganization -, 2- Unclear limited support development, 3-somewhat developed support, 4- developed, using appropriate and sufficient explanations, 5-All parts addressed and supported using clearly appropriate explanations Relevant/Focus 1, Little or No Examples, 2-mostly irrelevant, 3- somewhat relevant details 4- Mostly relevant details but lacking focus, 5- Relevant details and focused on question 


\section{Results}

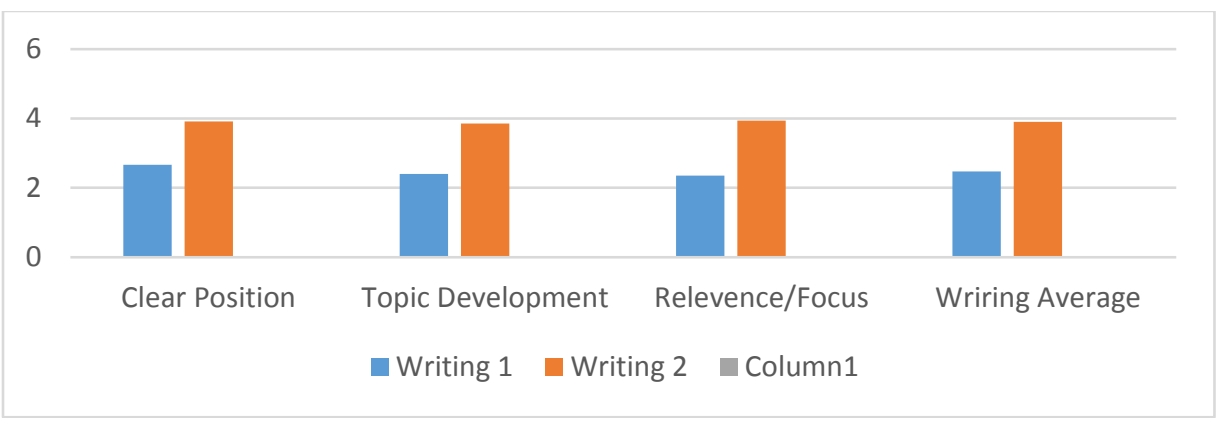

Figure 1. Average band score

Figure 1 shows that there was an easily visible increase across all categories from Writing I to Writing 2 .

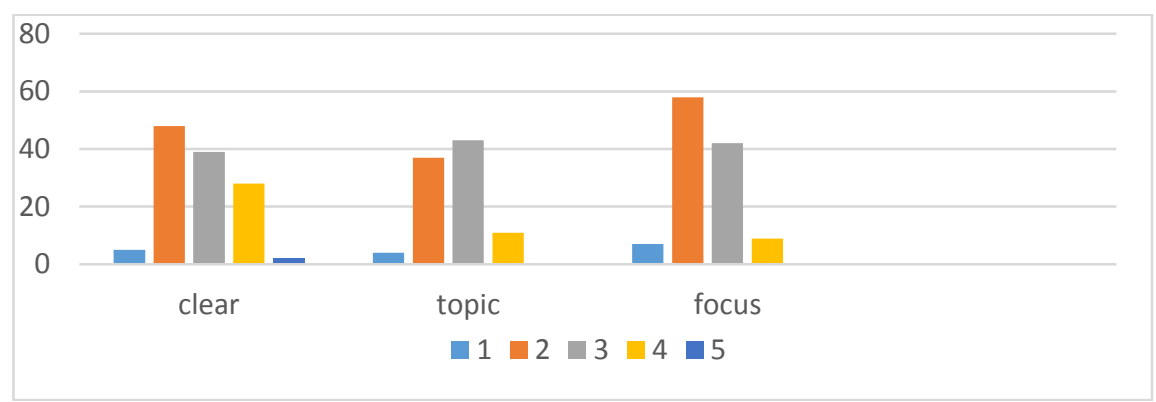

Figure 2. Writng I number of times each band score was awarded

Figure 2 shows that a score of 2 or 3 accounted for the majority of scores across categories and that Clear Position had a greater number of 4 and the only category to have any scores of 5 .

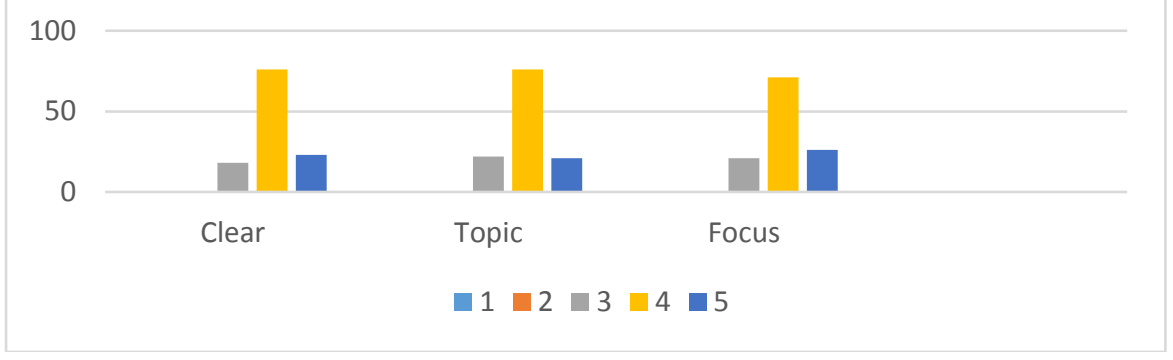

Figure 3. Writing II Number of Each Band Score

Figure 3 shows that the majority of papers were scored as 4 across all categories and that both 3 and 5 were almost even. There were no scores of 1 or 2 .

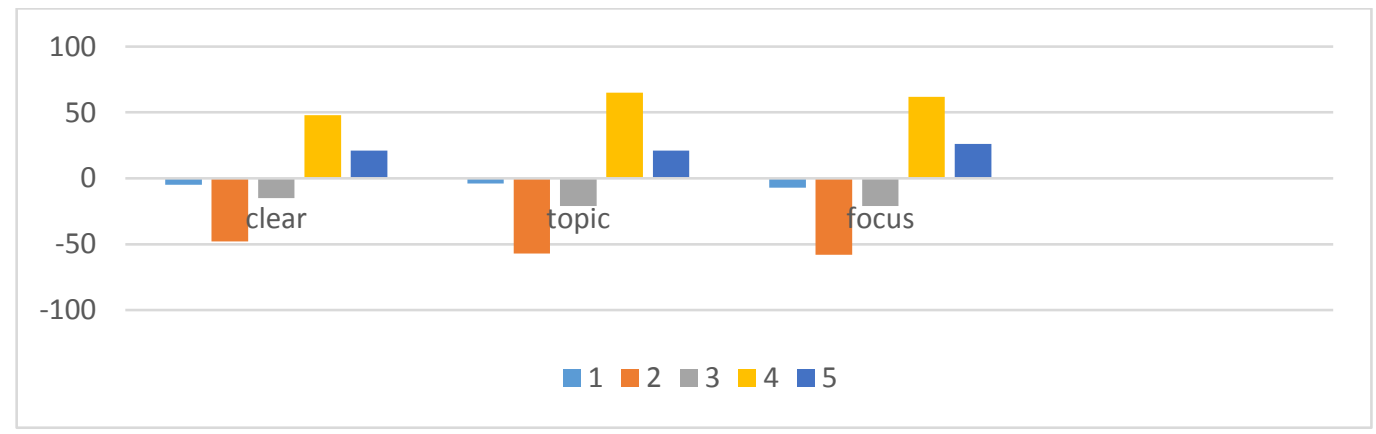

Figure 4. Change in the number of band scores awarded

Figure 4 shows that there was a decrease in the lower scale scores, with 2 rating taking the greatest fall. There was a marked increase in the two highest scale scores with the increase in 4 being the greatest. The elimination of Scale Scores 1 and 2 partially reflect that references to Newton, Aristotle and presumably myths from the Xia Dynasty were not employed in the Second Paper. While the drop 
in Scale Score 3 reflects the lessening of "some say A, while others say B" that serve only to hide the point trying to be made.

\section{Discussion}

The results show that the use of Oral Presentation had a marked impact upon Task Response. Increasing the clarity of the position through the use of a clear summary of the main idea and it's supporting ideas. It also improved the development of the supporting idea by increasing the relevance to the topic and by narrowing the focus through the elimination of superficial details. These results were made possible by three main factors, Duel Mode Interactive Feedback, Summary Requirement and PowerPoint structure, each of which are explained below.

\section{Dual Mode Interactive Feedback}

The design of the course presented the Instructor with two opportunities to engage in interactive feedback with students: first, at the time of the presentation and second, in the class following the presentation while other groups were working on their next presentation. In the first mode, questions that were more general and possibly thought provoking were asked. While in the second, questions that were more detail or focus oriented would be asked. This also allowed groups to ask for further clarification of the ideas that were generated in the first mode and about applying them to the next presentation.

\section{Summary Requirement}

This forces the students to clearly express both the main idea and its' supporting ideas together and thus allows for feedback about how the argument works as a whole. The requirement also offers an opportunity to interactively discuss ways in which the argument could be strengthened and whether or not some examples are appropriate to the position taken.

\section{PowerPoint Structure}

The five lines with five words maximum per line design of the PowerPoint eliminates the possibility of providing feedback below the sentence level and forces the feedback to focus on a more global level of the ideas expressed, both in individual slides and the presentation as a whole. Thus making the ideas and their relevance to the topic central to feedback.

\section{References}

[1] Information on https://www.ets.org/toefl/ibt/scores/understand

[2] Information on https://www.ielts.org/-/media/pdfs/writing-band-descriptors-task-1.ashx?la=en

[3] Jinjin Lu, Yingliang Liu, Learner Autonomy as an Element in Chinese Education Reform: A Case of English Language Subject English Language Teaching; Vol. 9, No. 3; 2016

[4] P Black, D William Assessment and classroom learning. Assessment in Education: Principles, Policy and Practice, 1998 5(1).

[5] D Nicol, D Macfarlane-Dick Formative Assessment and self-regulated learning: A model and seven principles of good feedback. Studies in Higher Education. 2006 31(2) 199-218.

[6] J J Hamed The effect of Peer Reviewing on Writing Apprehension and Essay Writing Ability of Prospective EFL Teachers. Australian J of Teacher Ed. 37.11 Article 4.

[7] Zheng Chun-xian A Study of Peer Error Feedback US-China Foreign Language Vol 5 No 4, Apr 2007 [8] L. Paul Mantha, Yan-Yan Yu, Han Van Triest, Increasing the Quality of Peer Feedback in a Professional Writing Course, International Conference on Education and Development (ICED 2016) 
[9] Junhong Ren, Na Wang A Survey on College English Writing in China: A Cultural Perspective English Language Teaching; Vol. 8, No. 1; 2015

[10] Information on https://owl.english.purdue.edu/owl/resource/685/05/ 